\title{
Fetal alcohol spectrum disorders: Prevalence rates in South Africa
}

\author{
L Olivier, ${ }^{1,2}$ BA Hons (Psych); L M G Curfs, ${ }^{3,4}$ MD; D L Viljoen, ${ }^{1,2}$ MB ChB, FCPaed, PhD \\ ${ }^{1}$ Foundation for Alcohol-Related Research (FARR), Cape Town, South Africa \\ ${ }^{2}$ Division of Molecular Biology and Human Genetics, Faculty of Health Sciences, Stellenbosch University and Tygerberg Hospital, Cape Town, \\ South Africa \\ ${ }^{3}$ Governor Kremers Centre, Maastricht University Medical Centre, Holland \\ ${ }^{4}$ Department of Genetics, Maastricht University Medical Centre, Holland
}

Corresponding author: L Olivier (lo@farrsa.org.za)

\begin{abstract}
Background. Fetal alcohol spectrum disorder (FASD) is an under-diagnosed condition in South Africa (SA). Fetal alcohol syndrome and FASD community prevalence studies were undertaken in 17 towns in three of the nine provinces in SA.

Objective. The objective for all the studies was to determine the FASD prevalence rates by assessing the grade 1 learners in all the studies, using international FASD diagnostic criteria.

Methods. The same methodology was used for all the studies in Gauteng, Western and Northern Cape provinces. Consenting grade 1 learners received anthropometric screening, clinical examinations and neurodevelopmental assessments. Structured interviews were used to assess maternal alcohol consumption during pregnancy.

Results. Reported prevalence rates ranged from 29 to 290 per 1000 live births.

Conclusion. FASD rates from studies conducted in SA are among the highest worldwide. FASD affects all communities in SA and is therefore a major public health concern in SA. Multidisciplinary and intersectoral interventions are urgently required to raise awareness about the dangers of prenatal alcohol exposure and the devastating effect of FASD on the lives of children, families and communities.
\end{abstract}

S Afr Med J 2016;106(6 Suppl 1):S103-S106. DOI:10.7196/SAMJ.2016.v106i6.11009

\section{Background}

Alcohol consumption in South Africa (SA) has a long and complex social, cultural and political history. First-nation South Africans consumed home-brewed alcoholic drinks as part of social and ritual events and used it as a mode of trade for cattle and merchandise. During the colonial times from 1652 to 1948 , settlers introduced the 'dop' system whereby farm workers were partially paid with alcohol for their labour. ${ }^{[1,2]}$ During the 'apartheid' era alcohol was used paternalistically to economically and socially control mine and farm workers. In an attempt to curb social deterioration, black South Africans were prohibited from using alcohol. Paradoxically, local authorities installed beerhalls (taverns) in black townships to enhance local economic development, but at the same time, exercising control over the inhabitants of these townships. ${ }^{[3]}$ This ambivalence led to resistance, with local residents opening their own illegal liquor outlets ('shebeens') and brewing their own beer. ${ }^{[4]}$ Since 2004, home-brewed beer has been increasingly replaced by industrial beverages. ${ }^{[5]}$

According to the World Health Organization Global Status Report on Alcohol and Health $2014,{ }^{[6]} 43.7 \%$ of SA males and $73.7 \%$ females above 15 years of age abstained from alcohol in 2013. In countries with a high abstention rate it is highly likely that the per capita consumption rate will be understated. This, as well as underreporting, provides some reasons why there is often a discrepancy in the reported absolute alcohol (AA) per capita consumption rate in SA. The report states the average SA consumption rate as $11 \mathrm{~L}$ AA per person ${ }^{[6]}$ while Peltzer and Ramlagan ${ }^{[5]}$ note a rate of between 10.3 and $12.4 \mathrm{~L}$, compared with a global average of $6.2 \mathrm{~L} .{ }^{[7]}$ This gives SA one of the highest alcohol consumption rates per drinker in the world. ${ }^{[5]}$ Peltzer and Ramlagan ${ }^{[5]}$ furthermore link the high burden of alcohol use to hazardous and harmful drinking resulting in social ills such as alcohol-related deaths in transport and due to homicide, risky sexual behaviour among persons living with HIV/AIDS, and a fetal alcohol syndrome (FAS) rate of 10 - 74 per 1000 grade 1 learners.

FAS as a burden of disease attributed to alcohol use in South Africa

Among the burdens of alcohol consumption is fetal alcohol spectrum disorder (FASD). FASD is an under-diagnosed umbrella term for a range of disorders caused by the teratogenic effects of alcohol on the developing fetus (Table 1). FAS, the most severe form of these disorders, was first described by Lemoine and colleagues in France in 1968, with Jones et al. ${ }^{[8]}$ coining the term in 1973. Replicating reports of the condition soon followed from Canada, European countries and SA.

FAS and FASD prevalence studies in South Africa In $\mathrm{SA}$, the condition remained under-reported until the end of the last century. The first FAS and partial FAS (pFAS) prevalence study was undertaken by May and Viljoen ${ }^{[10-12]}$ in the Western Cape Province in 1997, reporting rates of 46 per 1000 grade 1 learners in 1997, increasing to 74 per 1000 in 1999 and 89.2 per 1000 in 2001. In these studies, the focus was on FAS and pFAS involving all the consenting grade 1 learners in the study area.

Since 1997, various prevalence studies in SA have revealed FAS rates as high as 26 per 1000 in Gauteng; ${ }^{[13]} 64,74.7$, and 119.4 per 1000 in Upington, Kimberley and De Aar, Northern Cape, respectively; ${ }^{[14,15]} 6.7,9.6$ and 100 per 1000 in the Saldanha Bay Municipality, the Witzenberg sub-district, and Aurora on the West Coast, respectively; ${ }^{[16]}$ and 290 per 1000 in the Winelands area. ${ }^{[17]}$ The SA studies involve all the cultural groups living in these rural, peri-urban and urban communities (Fig. 1).

Two more evaluations are currently underway in a rural area in the Northern Cape and an urban area in the Eastern Cape. 
When compared with similar studies undertaken in other countries, such as the reported FASD rates of $10-15$ per 1000 in the USA; ${ }^{[18]}$ 10 per 1000 in Canada; ${ }^{[19]} 35$ per 1000 in Italy; ${ }^{[20]} 18$ per 1000 in France; ${ }^{[21]} 20$ per 1000 in Poland; ${ }^{[22]}$ and 12 per 1000 in Croatia, ${ }^{[23]}$ the extent of the SA FASD challenge is self-evident.

In a 2015 study in a rural community in Australia, a FAS rate of 120 per 1000 was reported, ${ }^{[24]}$ this being the first study outside of SA to report figures close to the SA rates. In 2006, the National Institute on Alcohol Abuse and Alcoholism already raised concern for this 'large and rapidly increasing public health problem. ${ }^{[25]}$

\section{Methods}

In all the SA community prevalence studies mentioned above, the prevalence of FAS and FASD was determined by active case ascertainment, using a tiered screening and diagnostic approach that were validated and used in SA before. ${ }^{[10,11]}$ The studies were conducted on invitation only. These invitations were received from government departments, local municipalities and/or community leaders. Approval was obtained from the Health Research Ethics Committees of either the University of the Witwatersrand (until 2005) or Stellenbosch University (since 2005) and the relevant Provincial Departments of Education in SA. All the studies involved grade 1 learners (school entry level, 6 years or older) attending all the schools in the research area, or from randomly selected schools

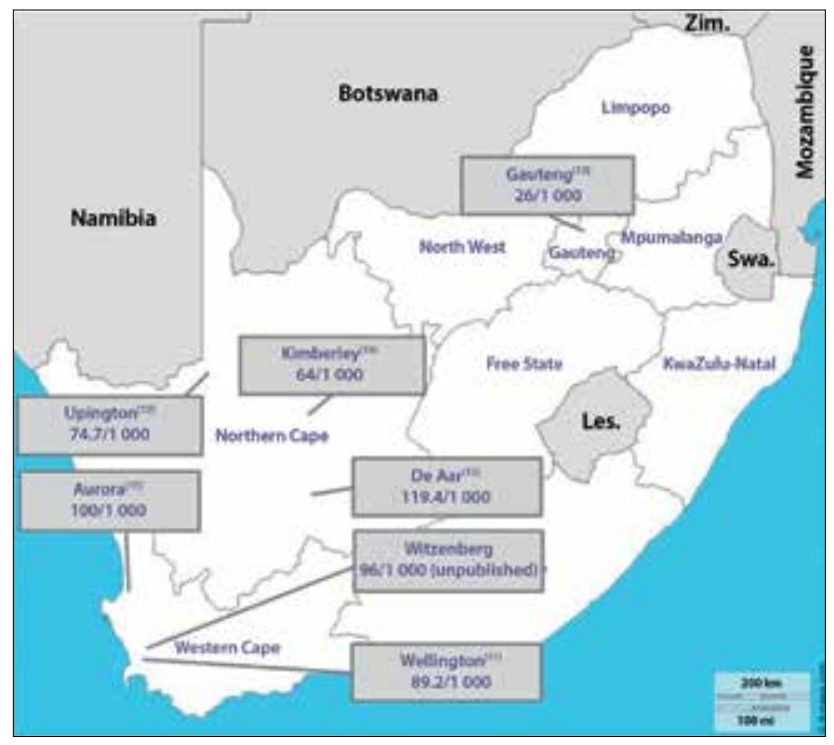

Fig. 1. FAS prevalence study sites and rates per 1000 live births.
(Witzenberg sub-district). Parents/guardians of these children were invited to enrol their children in the study by signing an informed consent form. They could withdraw their children at any time during the study. Demographic data pertaining to names, addresses and dates of birth were obtained from the schools.

\section{Screening and clinical assessments}

A research team visited the schools on pre-arranged dates; parents/ guardians were encouraged to attend these sessions. Members of the research team were blinded to the findings of other team members throughout the studies. Anthropometric assessments of head circumference (OFC) growth and height, as well as general physical examinations, were undertaken by Primary healthcare nursing professionals with the support of community workers. As many of the studies were conducted in under-resourced areas, the physical examinations were important and detected a number of health and psychosocial problems unrelated to FASD. All of these were managed by the research team or through referrals if the relevant resources were available. The Centers for Disease Control and Prevention clinical growth charts were used to determine individual learners' centiles. ${ }^{[26]}$ If a learner's measurements were $\leq 10$ th centile on OFC and/or height and weight, he/she was referred for a dysmorphology exam by an experienced medical doctor (also qualified as a human geneticist and paediatrician). The Hoyme checklist ${ }^{[27]}$ was adapted to develop a standardised assessment tool yielding a dysmorphology score with a maximum of 50 . The dysmorphology features included the primary facial features of FAS such as short palpebral fissures, narrow upper vermillion border, smooth philtrum of the upper lip. ${ }^{[15]}$ School educators could also refer consented grade 1 learners with learning, health or psychosocial problems.

Learners with a dysmorphology score of $11 / 50$ or higher were referred for neurodevelopmental assessments and maternal interviews. All the grade 1 learners, irrespective of whether they participated in the study or not, received refreshments (fruit juice and a muffin).

\section{Maternal interviews}

Community workers were trained to use standardised questionnaires to interview biological mothers or guardians. The questionnaire was developed and refined by May and Viljoen ${ }^{[28-30]}$ and further adapted in an unpublished Masters study ${ }^{[31]}$ Information was gathered to determine maternal risk factors before, during and after the gestation of the index child, pertaining to the mother's nutritional and health status, alcohol and nicotine usage, socioeconomic status, educational level, and the child's birth weight and health status immediately

\section{Table 1. Key concepts and terms as described by Stratton et al. ${ }^{[9]}$ from the Institute of Medicine in 1996}

Prenatal alcohol exposure refers to the fetus being exposed to any amount of alcohol consumed by the biological mother during her pregnancy.

Fetal alcohol spectrum disorders (FASD) is an umbrella term used for a group of permanent, life-long and irreversible conditions caused by the teratogenic effects of alcohol on the fetus. The Institute of Medicine acknowledges the following four categories:

- Fetal alcohol syndrome (FAS) is the most severe form of FASD with at least 2 characteristic facial features, growth retardation (height and weight), head circumference $<10$ th centile, and central nervous system damage with neurodevelopmental delays. A history of regular and/or heavy maternal prenatal alcohol exposure may be present or unknown.

- Partial fetal alcohol syndrome (pFAS) is characterised by some of the discriminating facial features, as well as growth retardation and neurodevelopmental delays. A confirmed history of prenatal alcohol use might be present or not.

- Alcohol-related neurodevelopmental deficits (ARND) refer to structural and/or functional central nervous system damage with neurodevelopmental delays with a confirmed history of prenatal alcohol exposure.

- Alcohol-related birth defects (ARBD) are characterised by congenital skeletal, cardiac, eye, kidney or other organ imperfections with a confirmed history of prenatal maternal alcohol use. 
after birth. During the interview, both the interviewer (community worker) and the mother/guardian were unaware of the FASD status of the child. Interviewees received a food voucher (ZAR85) to be used at a local food store as an incentive.

\section{Neurodevelopmental assessments}

Neurodevelopmental assessments were done by trained psychologists and an occupational therapist, using the Griffiths Mental Developmental Scales-Extended Revised (GMDS-ER). ${ }^{[32]}$ Six developmental domains, namely locomotor (gross motor skills), eye-hand (fine motor coordination), personal-social (adaptive functioning), hearing-speech (verbal ability), performance (pattern construction and speed of performance) and practical reasoning (numerical, time and spatial concepts) were assessed. ${ }^{[15]}$ For each domain, raw scores were converted to $z$-scores and ultimately a GQ (general quotient as an aggregated scored based on all 6 sub-domains on which the learner is tested). Two or more standard deviations below the mean of the GMDS-ER were indicative of a significant delay. ${ }^{[33]}$

\section{Case conference}

Final diagnoses were made in a case conference, using the Hoyme criteria $^{[27]}$ for the diagnostic categories FAS, pFAS, ARBD, ARND and 'not FASD'.

To verify a diagnosis of FAS, at least two of the three discriminating facial features, plus growth retardation and neurodevelopmental delay with or without prenatal alcohol exposure, were required. pFAS was diagnosed when two of the three FAS facial features were present, as well as growth retardation and neurodevelopmental delay, plus a maternal history of alcohol consumption during pregnancy. To confirm a diagnosis of ARND, confirmed maternal alcohol use and neurodevelopmental delays, unrelated to any other reason, were required. A diagnosis of ARBD was made when a birth defect such as a heart murmur was present, as well as a history of prenatal alcohol

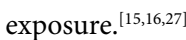

Due to limitations related to the study and the instruments used, the primary focus was on the identification of FAS. The researchers therefore acknowledge that most cases of ARND, and ARBD, and even some cases of pFAS, were missed. Therefore, the FASD rates in the research sites could in fact be higher than reported.

\section{Discussion}

The published FASD prevalence rates in SA unfortunately indicate that our country has the highest reported rates of this permanently crippling but totally preventable condition. In some of the researched areas, the prevalence of FASD is higher than the HIV/AIDS or tuberculosis rates, but it is yet to be acknowledged as a public health priority by the National Department of Health. Governmental prevention and awareness programmes are limited to a few highrisk areas in the Northern Cape (Kimberley, De Aar and Upington) and the Western Cape (Witzenberg and West Coast). The greatest awareness initiative at present in $\mathrm{SA}$ is, as controversial as it might be, driven by the wine and beer beverage industry. This is despite the constant threat of the National Minister of Health to ban alcohol advertising in SA. With the exception of the Vredenburg/Saldanha municipal area in the Western Cape, the industry is currently funding all the FASD training in SA provided to government employees in the Northern, Eastern and Western Cape provinces.

The unfortunate delay in the acknowledgement of this devastating but highly preventable disorder and the reluctance to take action are costing the current and future communities in SA dearly. The cost to families, communities and the country at large has a lifelong crippling effect on the psychosocial, vocational and overall wellbeing of the nation. A concerted effort involving the relevant government departments, civil society, private industry and the SA community at large is needed to break the cycle of misfortune perpetuating the ever-increasing FASD epidemic in SA.

Acknowledgements. Without the cooperation of the parents/guardians and participating children these studies would not have been possible. The support of the various school principals and educators on all the study sites was admirable. Special acknowledgement goes to the dedicated staff of the Foundation for Alcohol-Related Research. The healthcare facilities and social services are thanked for the management of referrals. The generous support and sponsorships of the funders and philanthropists who funded the research and prevention programmes are acknowledged. The Departments of Social Development in the Northern Cape and Western Cape provinces are thanked for funding the research in Kimberley and the Saldanha Bay District. The Provincial Departments of Education and Health (Western and Northern Cape provinces), as well as the Research Ethics Committees of the Witwatersrand and Stellenbosch universities, are thanked for granting ethical approval for the studies.

Conflict of interest. The Foundation for Alcohol-Related Research received funding for awareness and training programmes from the Industry Association for Responsible Alcohol Use, the South African Breweries and Distell Foundation.

\section{References}

1. London L, Sanders D, te Water Naude J. Farm workers in South Africa - the challenge of eradicating alcohol abuse and the legacy of the 'dop' system. S Afr Med J 1998;88(9):1092-1095.

2. London L. Alcohol consumption amongst South African farm workers: A challenge for post-aparthei health sector transformation. Drug Alcohol Depend 2000;59(2):199-206. DOI:10.1016/s03768716(99)00120-9

3. Parry CDH. South Africa: Alcohol today. Addiction 2005;100(4):426-429. DOI:10.1111/j.13600443.2005.01015.x

4. Schneider M, Norman R, Parry C, Bradshaw D, Pluddemann A. South African Comparative Risk Assessment Collaborating Group. Estimating the burden of disease attributable to alcohol use in South Africa in 2000. S Afr Med J 2007;97(8Pt2):664-672.

5. Peltzer K, Ramlagan S. Alcohol use trends in South Africa. J Soc Sci 2009;18(1):1-12.

5. Peltzer K, Ramlagan S. Alcohol use trends in South Africa. Soc Sci 2009;18(1):1-12.
6. World Health Organization. Global Status Report on Alcohol and Health 2014. Geneva: WHO, 2014; $1-392$.

7. Rehm J, Mathers C, Popova S, Thavorncharoensap M, Teerawattananon Y, Patra J. Global burden of disease and injury and economic cost attributable to alcohol use and alcohol-use disorders. Lancet disease and injury and economic cost attributable to alcohol use

8. Jones KL, Smith DW, Ulleland CN, Streissguth P. Pattern of malformation in offspring of chronic 8. Jones KL, Smith DW, Ulleland CN, Streissguth P. Pattern of malformation in offspring
alcoholic mothers. Lancet 1973;1(7815):1267-1271. DOI:10.1016/s0140-6736(73)91291-9

9. Institute of Medicine. Fetal Alcohol Syndrome: Diagnosis, epidemiology, prevention, and treatment. In: Stratton, K, Howe, C, Battaglia F, eds. Washington, DC: National Academies Press, 1996. DOI:10.17226/4991

10. May PA, Brooke L, Gossage JP, et al. Epidemiology of fetal alcohol syndrome in a South African community in the Western Cape Province. Am J Public Health 2000;90(12):1905-1912. DOI:10.2105 ajph.90.12.1905

11. Viljoen DL, Gossage IP, Brooke L, Adnams CM, Jones KL, Robinson LK, et al, Fetal alcohol syndrome epidemiology in a South African community: A second study of a very high prevalence area. J Stud Alcohol 2005;66(5):593-604. DOI:10.15288/jsa.2005.66.593

12. May PA, Gossage JP, Marais A-S, et al. The epidemiology of fetal alcohol syndrome and partia FAS in a South African community. Drug Alcohol Depend 2007;88(2-3):259-271. DOI:10.1016/. drugalcdep.2006.11.007

13. Viljoen DL, Craig P, Hymbaugh K, Boyle C, Blount S. Fetal alcohol syndrome - South Africa, 2001. Morb Mortal Wkly Rep 2003;52(28):660-662.

14. Urban M, Chersich MF, Fourie L-A, Chetty C, Olivier L, Viljoen D. Fetal alcohol syndrome among Grade 1 school children in Northern Cape Province: Prevalence and risk factors. S Afr Med J 2008;98(11):877-882.

15. Urban MF, Olivier L, Vilioen D, et al. Prevalence of fetal alcohol syndrome in a South African city with a predominantly Black African population. Alcohol Clin Exp Res 2015;39(6):1016-1026. DOI:10.1111 a predominat

16. Olivier L, Urban M, Chersich M, Temmerman M, Viljoen D. Burden of fetal alcohol syndrome in a rural West Coast area of South Africa. S Afr Med J 2013;103(6):402-405. DOI:10.7196/samj.6249

17. May PA, Blankenship J, Marais A-S, et al. Approaching the prevalence of the full spectrum of fetal May PA, Blankenship J, Marais A-S, et al. Approaching the prevalence of the full spectrum of fetal
alcohol spectrum disorders in a South African population-based study. Alcohol Clin Exp Res alcohol spectrum disorders in a South African population-based study. Alcohol Clin Exp Res 2013;37(5):818-830. DOI:10.1111/acer.1203

18. Riley EP, Infante MA, Warren KR. Fetal alcohol spectrum disorders: An overview. Neuropsychol Rev 2011;21(2):73-80. DOI:10.1007/s1 1065-011-9166-x

19. Stade B, Ali A, Bennett D, et al. The burden of prenatal exposure to alcohol: Revised measurement of cost. Can J Clin Pharmacol 2009;16(1):e91-e102.

20. May PA, Fiorentino D, Coriale G, et al. Prevalence of children with severe fetal alcohol spectrum disorders in communities near Rome, Italy: New estimated rates are higher than previous estimates. Int J Environ Res Public Health 2011;8(6):2331-2351. DOI:10.3390/ijerph8062331

21. Chazeron I, Llorca P-M, Ughetto S, et al. Is pregnancy the time to change alcohol consumption habit in France? Alcohol Clin Exp Res 2008;32(5):868-873. DOI:10.1111/j.1530-0277.2008.00646.x

22. Okulicz-Kozaryn K, Borkowska M, Brzozka K. FASD prevalence among schoolchildren in Poland. J Appl Res Intellect Disabil 2015. DOI:10.1111/jar.12219 
23. Petković G, Barišić I. Prevalence of fetal alcohol syndrome and maternal characteristics in a sample of schoolchildren from a rural province of Croatia. Int J Environ Res Public Health 2013;10(4):1547 1561. DOI:10.3390/ijerph10041547

24. Fitzpatrick JP, Elliott EJ, Latimer J, et al. The Lililwan Project: Study protocol for a population-based active case ascertainment study of the prevalence of fetal alcohol spectrum disorders (FASD) in remote
and active case ascertainment study of the prevalence of fetal alcohol spectrum disorders (FASD) in remote
Australian Aboriginal communities. BMJ Open 2012;2(3):e000968. DOI:10.1136/bmjopen-2012-000968 Australian Aboriginal communities. BMJ Open 2012;2(3):e000968. DOI:10.1136/bmjopen-2012-000968
25. Calhoun F, Attilia ML, Spagnolo PA, Rotondo C, Mancinelli R, Ceccanti M. National Institute on 25. Calhoun F, Attilia ML, Spagnolo PA, Rotondo C, Mancinelli R, Ceccanti M. National Institute on
Alcohol Abuse and Alcoholism and the study of fetal alcohol spectrum disorders. The International Consortium. Ann 1st Super Sanita 2006;42(1):4-7.

26. Centers for Disease Control and Prevention, National Center for Health Statistics. Growth Charts. Atlanta, Georgia: Centers for Disease Control, 2010. http://www.cdc.gov/growthcharts/ (accessed 20 November 2015). 27. Hoyme HE, May PA, Kalberg WO, et al. A practical clinical approach to diagnosis of fetal alcohol spectrum disorders: Clarification of the 1996 Institute of Medicine criteria. Pediatr 2005;115(1):39-47. 28. May PA, Gossage JP, Brooke LE, et al. Maternal risk factors for fetal alcohol syndrome in the Western
Cape Province of South Africa: A population-based study. Am J Public Health 2005;95(7):1190-1199. DOI:10.2105/ajph.2003.037093

29. May PA, Gossage JP, Marais A-S, et al. Maternal risk factors for fetal alcohol syndrome and partial fetal alcohol syndrome in South Africa: A third study. Alcohol Clin Exp Res 2008;32(5):738-753. DOI:10.1111/j.1530-0277.2008.00634

30. Viljoen D, Croxford J, Gossage JP, Kodituwakku PW, May PA. Characteristics of mothers of children with fetal alcohol syndrome in the Western Cape Province of South Africa: A case control study. J Stud Alcohol 2002;63:6-17.

31. Breytenbach B. A revision of a maternal interview questionnaire used in fetal alcohol spectrum disorder prevention programmes in South Africa. Doctoral dissertation, Stellenbosch University. 2014. 2. Griffiths R. The ability of young children: A comprehensive system of mental measurement for the first eight years of life. Oxford: The Test Agency, 1970.

33. Luiz D, Faragher B, Barnard A, et al. Griffiths Mental Developmental Scales-Extended Revised - Two to Eight Year. Anal Man, 2006

\section{Foundation for Alcohol Related Research (FARR)}

FARR was established in 1997 to conduct South Africa’s first FASD (fetal alcohol spectrum disorder) prevalence study. Since then, FARR has evolved to become one of the leading organisations in South Africa with regards to not only world-class research, but also in FASD prevention and intervention.

FARR's mission is to establish sustainable awareness, prevention, intervention and training programmes designed to eliminate

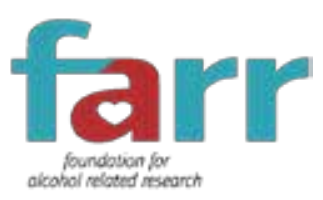
substance abuse, with the focus on FASD as preventable disorder in South Africa.

During the 3 year-projects conducted by FARR, we conduct comprehensive research in a designated area and implement our Healthy Mother Healthy Baby@ prevention programme. The programme focuses on assisting pregnant women in having healthier, substance and alcohol-free pregnancies to ensure the birth of healthier babies. Awareness programmes are also implemented involving the community at large, all possible stakeholders and service providers as well as the atrisk individuals. Finally, FARR's Training Academy provides specialised training courses for service providers, educators, health care professionals, social workers, therapists, etc.

In 2014, FARR established an FASD Support Group that aims at providing support and guidance for biological and foster parents, as well as guardians of children with FASD.

\section{Contact details:}

For more information, please contact us at:

Tel: 0216862646

Email: info@farrsa.org.za

Website: www.farrsa.org.za

FASD Support Group: 0731253459 or email: fasdsupportgroup@farrsa.org.za 